\title{
ACOMPANHAMENTO DE EGRESSOS DO ENSINO SUPERIOR: experiência brasileira e internacional ${ }^{1}$
}

\author{
Jean-Jacques Paul*
}

\begin{abstract}
Este artigo traça um panorama das diversas experiências de acompanhamento de egressos do ensino superior, destacando as metodologias utilizadas nos diferentes países ou em projetos internacionais. Os dispositivos de acompanhamento resultam de políticas governamentais ou de instituições autônomas e visam a dar maior visibilidade ao sistema de ensino superior cada vez mais complexo. Fornecendo subsídios essenciais para a avaliação dos resultados dos sistemas educativos, os dispositivos de acompanhamento atingiram os melhores indicadores de funcionamento no caso italiano, Alma Laurea. No Brasil, há experiências díspares, começando nos anos 1970, passando pelos estudos na USP e UFC no início dos 1990, até o estágio atual, com a proliferação de portais de egressos. Constituem exigências metodológicas do acompanhamento, conforme indica a experiência: caráter institucional sistemático e participativo; periodicidade regular e atualização permanente; utilização de tecnologias da informação para coleta de dados; definição clara e adequada da população a ser atingida, segundo os tipos de diplomas; produção de escalas adequadas para a avaliação dos destinos ocupacionais e sua relação com a formação; e disponibilização dos bancos de dados para a comunidade acadêmica.
\end{abstract}

Palavras-chave: Ensino Superior. Dispositivos de acompanhamento. Avaliação. Egressos. Destinos ocupacionais.

\section{INTRODUÇÃO}

Já faz mais de quarenta anos que as pesquisas de egressos do ensino superior se generalizaram. Com exceção de alguns estudos sobre os egressos em países socialistas e em outros países em desenvolvimento, ${ }^{2}$ a maior parte deles tratava, sobretudo, dos países desenvolvidos liberais, cujos sistemas de ensino superior viram seus efetivos (matrículas, egressos, docentes) multiplicarem-se nos anos 1960. Essas pesquisas, muitas vezes iniciadas por sociólogos e economistas interessados na transformação do ensino superior e nas evoluções do mercado de trabalho, foram, gradualmente, retomadas pelos centros estatísticos governamentais - como na França - ou incor-

\footnotetext{
* Universidade da Borgonha em Dijon, França. Universidade de Galatasaray. Istambul, Turquia.

Ortaköy, Çırağan Cd. No:36, 34349 Beşiktaş/İstanbul, Turquia.jjpaul.gsu@gmail.com

${ }^{1}$ Trabalho apresentado no Seminário Internacional sobre Democratização do Ensino Superior, realizado no PPGSA/ UFRJ em novembro de 2013. Tradução de Malou Paul, revisão M. Ligia Barbosa

${ }^{2}$ Ver, especialmente os trabalhos de Sanyal, do Instituto Internacional de Planejamento da Educaçã̃o, referenciados neste texto
}

poradas em sistemas autônomos nacionais como nos casos da Grã-Bretanha e da Itália. No Brasil, embora algumas pesquisas tenham sido realizadas na década de 1980 e os "Portais do Egresso" tenham proliferado nos últimos anos, os estudos de egressos continuam esporádicos, pouco utilizados e com insuficiências metodológicas que podem estar associadas à falta de observação das experiências internacionais.

Começaremos recapitulando alguns estudos pioneiros nos países desenvolvidos, de orientações políticas liberais, assim como as experiências internacionais mais significativas atualmente, para abordar, em seguida, a situação das pesquisas de egressos do ensino superior no Brasil.

\section{CONTEXTO E PRIMEIRAS EXPERI- ÊNCIAS}

Excetuando-se alguns trabalhos precursores e ocasionais nos Estados Unidos na década de 1930, as primeiras pesquisas de egressos surgiram apenas nos anos 1960, estendendo-se nos anos 1970 e 1980. Os Estados Unidos e a 
França se distinguem quanto ao início dos estudos: enquanto os primeiros, nos anos 1960, iniciaram amplas pesquisas longitudinais, a França começou, nos anos 1970, por meio da implementação de dispositivos nacionais de pesquisa. Mas a situação atual apresenta um quadro diferente, no qual se destacam outras experiências nacionais.

\section{CONTEXTO}

O interesse pelo futuro profissional dos egressos do ensino superior, o qual se afirma nos anos 1970, inscreve-se em um contexto de transformação quantitativa e organizacional do ensino superior, situado, por sua vez, em uma profunda evolução do mercado de trabalho.

Desde os anos 1960-70, as matrículas do ensino superior dispararam. Na Europa, em especial na França, eles triplicaram entre 1970 e 2010. ${ }^{3}$ Na América Latina, os números de matrículas foram multiplicados por onze e no Brasil por quinze. Na França, em uma geração, $42 \%$ dos jovens estão saindo do sistema educativo com um diploma do ensino superior, contra 15\% em 1985 e 32\% em 1995.

As estruturas do ensino superior também evoluíram significativamente no decor$\stackrel{2}{5}$ rer dos últimos trinta anos. Se a universidade : continua sendo a instituição de referência na $\stackrel{8}{\Delta}$ maioria dos países, outras instituições surgiram ou se consolidaram. De acordo com Teichler (2011), o processo de Bolonha, iniciado em 1999, que levou à implantação do Espaço Europeu de Ensino Superior em 2010, ${ }^{4}$ está ‡i longe de ter alcançado um modelo universitá¿ rio único.

${ }^{4}$ Trata-se de uma estrutura em três ciclos do ensino superior, sistema comum de créditos, mesmo modelo de suplemento ao diploma. municipais - e privados, com ou sem fins lucrativos, religiosos ou não, etc.) e departamentos com níveis de prestígio muito diferentes. É particularmente o caso do Brasil, sobretudo com a chegada de universidades privadas gigantescas, ligadas a grupos internacionais e com capital aberto, cotadas em bolsa.

Os títulos associados aos diplomas podem ser muitos. Na França, havia mais de 300 certificados diferentes de Licence générale, o que levou o Ministério do Ensino Superior a editar um texto legal, em julho de 2013, reduzindo o número desses títulos.

Simultaneamente, as modalidades de obtenção dos diplomas se diversificaram. Além do sistema de aprendizagem tradicional nos países de cultura germânica, os estágios se multiplicam por toda parte. Na França, 30\% dos estudantes do último ano de Licence générale estagiam em empresas, sendo que essa proporção sobe para $60 \%$ entre os alunos do $2^{\circ}$ ano de Master, nível de estudos pós-graduados (Capelle, 2014). As viagens ao exterior, durante os estudos, são também cada vez mais frequentes. Atualmente, na França, 16\% dos estudantes de ensino superior já tiveram uma experiência de estudos no exterior diretamente relacionada ao curso superior que estão realizando. São também cada vez mais numerosos os estudantes que decidem interromper temporariamente os estudos para dedicar um ano a uma experiência profissional específica, em geral associada a uma viagem ao exterior. Recorrer à internet mediante cursos on line abertos e em massa (em inglês, MOOC: massive open online course) também representa uma mudança nas modalidades de transmissão de conhecimentos.

O conjunto desses elementos, que fazem do ensino superior um universo cada vez mais complexo num contexto evolutivo de trabalho, exige um sistema de informação confiável e transparente quanto ao seu modo de funcionamento e aos seus resultados. Essas informações são necessárias tanto para entender o funcionamento social do sistema como para ajudar os poderes públicos, as famílias e os es- 
tudantes a definirem suas opções em termos de financiamento e de carreira.

Na França, foi a criação de novos diplomas que suscitou as primeiras pesquisas nacionais de inserção de graduados do ensino superior. $^{5}$ Naquela época, essa abordagem inscrevia em uma preocupação mais geral de monitoramento do sistema de formação vinculado a um sistema de planejamento indicativo nacional.

E foi nesse contexto que nasceu, em 1970, o Centro de Estudos e de Pesquisas sobre as Qualificações (Céreq), sob a tutela do Ministério da Educação e do Ministério do Trabalho.

O Céreq tem como base de estudos as

[...] condições de passagem dos indivíduos do aparelho de formação à atividade, segundo os tipos e os níveis de formação e qualquer que seja a natureza dos estabelecimentos de ensino: escolas técnicas, centros de formação para adultos, universidades. O objeto desses estudos é o de identificar os canais de acesso à profissão e as ocupações de início de carreira nas empresas, como também o de realçar os pontos críticos e de empreender estudos longitudinais de evolução das carreiras (Flavigny; Grelet, 2012). ${ }^{6}$

As exigências de prestação de contas por parte das universidades tornaram-se também cada vez mais constringentes, acentuadas pelos procedimentos de acreditação em certas áreas (faculdades de administração e de engenharia) e em inúmeros países. Na França, a partir da lei relativa "à liberdade e às responsabilidades das universidades" de 2007, as universidades devem publicar suas estatísticas incluindo os indicadores de aprovação nos exames e no fim dos ciclos, de prosseguimento de estudos e de inserção profissional dos estudantes; devem ainda publicar um relatório sobre a quantidade e a qualidade dos estágios realizados pelos estudantes com o objetivo de auxiliá-los em sua inserção profissional.

O Brasil não fica muito atrás no que diz

${ }^{5}$ Isso aconteceu em 1969, com as entrevistas dos egressos das duas primeiras promoções do novo diploma universitário de tecnologia, instaurado em 1965 (Flavigny; Grelet, 2012).

${ }^{6}$ Dossiê Céreq n. 5, 1973. respeito a essas exigências crescentes em matéria de prestação de contas: desde as primeiras experiências de avaliação dos programas de doutoramento e de mestrado efetuadas pela CAPES em 1977, até a implantação do sistema nacional de avaliação do ensino superior, regido pela lei de avaliação institucional de 2004. As avaliações feitas, desde 1997, por comitês paritários das universidades e dos programas, se generalizaram. Todavia, os critérios de qualidade de acesso ao mercado de trabalho não são, em geral, levados em conta, embora tenham surgido algumas experiências pontuais que veremos mais adiante.

Certos governos procuram também atender claramente às necessidades de informação dos estudantes e de suas famílias em matéria de inserção profissional. O UK Quality Code for High Education, estabelecido em 2012 na Grã -Bretanha, pretende ajudar as instituições de ensino superior a responder às expectativas dos estudantes tendo em vista a preparação da futura carreira, e a preparar seus formandos para enfrentar as demandas flutuantes do mercado de trabalho. Para que os serviços de orientação possam esclarecer os estudantes, as instituições são convidadas a recolher informações sobre o futuro deles, as quais devem ir além de dados sobre os primeiros empregos costumeiramente solicitados por agências estatísticas.

Desde muito tempo, os pesquisadores em economia e sociologia participam do desenvolvimento de pesquisas de inserção e de trajetória no mercado de trabalho e delas tiram proveito. Na França, foram dois demógrafos Girard e Bastide - que iniciaram as primeiras coletas. Na Europa, pesquisas importantes foram dirigidas a partir de estudos sobre o futuro profissional dos formandos. Deve-se salientar, a esse respeito, a contribuição extraordinária de Ulrich Teichler, do International Center for Higher Education Research, da Universidade de Kassel, Alemanha. Esse pesquisador não apenas desenvolveu as pesquisas com egressos do ensino superior na Alemanha, como também é o responsável por vários projetos 
internacionais baseados nelas. O projeto mais famoso é, sem dúvida, "Ensino Superior e Emprego dos Graduados na Europa”, mais conhecido por CHEERS, cujo objetivo foi o de analisar o emprego e o trabalho dos egressos de instituições de ensino superior em nove países europeus nos primeiros anos após a formatura.

\section{AS PRIMEIRAS EXPERIÊNCIAS}

Os Estados Unidos ocupam um lugar especial, pois realizam, há muitos anos, pesquisas em grande escala e em vários lugares sobre o futuro dos estudantes. Trata-se, frequentemente, de pesquisas baseadas em populações oriundas do ensino secundário, e são poucas as que se referem aos graduandos do ensino superior. É o caso, por exemplo, do projeto TALENT, com certeza o dispositivo mais ambicioso em termos de abrangência. Houve ainda pesquisas longitudinais de amostras de população de graduados do ensino superior, como o National Longitudinal Survey, que será apresentado mais adiante.

O projeto TALENT nasceu da vontade de se obter, a partir de uma visão global dos Estados Unidos, uma boa compreensão dos mecanismos de escolha de carreira e das relações $\stackrel{2}{5}$ entre a formação e o emprego, que poderiam . servir de base a um sistema de informação proalunos passaram por uma bateria de testes durante dois dias, o que correspondia a $5 \%$ de todos os alunos de segundo ciclo das escolas secundárias dos Estados Unidos. Esses alunos $\stackrel{2}{*}$ foram acompanhados longitudinalmente por $\therefore$ um, cinco e onze anos depois de formados. No

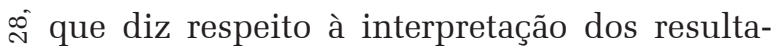
$\therefore$ dos, alguns autores utilizaram os dados para analisar expressamente a evolução da situação dos antigos estudantes do superior (French; Cook, 1969). Mas a principal utilidade do projeto refere-se à construção de um guia de informação profissional. A consulta desse guia revela, entretanto, os perigos da utilização de tal procedimento. Na verdade, os resultados dos testes, assim como a análise da vida acadêmica e dos empregos ocupados, permitiram a elaboração de um esquema de correspondência entre características individuais e características do emprego, cujos riscos de erros podem ser facilmente imaginados se não se leva em conta a margem de incertezas que acompanha os resultados dos testes, tampouco a evolução do sistema econômico.

Os National Longitudinal Surveys foram realizados pelo Center for Human Resource Research da Universidade do Estado de Ohio, EUA, contratado pelo Ministério do Trabalho. Iniciadas em 1966, essas pesquisas tinham por objetivo explicar o comportamento e a experiência profissionais de quatro coortes da população civil dos Estados Unidos, definidas por idade e sexo: homens entre 45 e 59 anos e de 14 a 24 anos em 1966, mulheres entre 30 e 44 anos em 1967 e mulheres que tinham entre 14 e 24 anos em 1968. As amostras foram inquiridas regularmente ao longo de quinze anos.

De acordo com H. Parnes (1978) “[...] pode-se afirmar, com toda sinceridade, que os National Longitudinal Surveys reúnem os dados mais completos, nunca antes recolhidos nas amostras da população nacional, que permitem a análise do comportamento e da experiência profissionais."

Outros estudos foram feitos com populações mais circunscritas de estudantes. Um dos primeiros dizia respeito ao futuro dos graduados do ensino secundário do Minnesota, no final dos anos 1930, sendo até mesmo prolongado por um estudo longitudinal.

Em 1957, cinco mil graduados (homens) do ensino secundário do Wisconsin foram submetidos a uma pesquisa que também serviu de base aos trabalhos de Sewel e Hauser (1975). Em 1975, foi feito novo contato com a mesma população, por telefone, e 88\% desses homens foram entrevistados.

A pesquisa do National Opinion Research Center dirigiu-se a uma população de estudantes do ensino superior. Tratava-se de uma 
amostra de graduados de junho de 1961 e, antes que saíssem do sistema de ensino, foram inquiridos a respeito de seus projetos profissionais. Durante três anos consecutivos, essas pessoas foram contatadas, e uma quinta entrevista foi ainda realizada em 1968 para conhecer a situação profissional após sete anos da obtenção do diploma. Dessa forma, cerca de cinco mil questionários puderam ser explorados.

A França apresenta um caso bastante singular de dispositivo nacional, coordenado do começo ao fim pelo Governo. Se o Céreq foi o responsável por empreender, no início dos anos 1970, as primeiras pesquisas junto a populações específicas - titulares de novos tipos de diplomas -, seus pesquisadores deduziram rapidamente que, para analisar a situação profissional dessas populações, seria necessário posicioná-las considerando o conjunto de todos aqueles que ingressaram na vida ativa; somente dessa forma seria possível comparar a situação desses formados em relação a outros graduados e comparar os efeitos de concorrência e de substituição entre os diplomas.

Da mesma forma, para que fossem levados em conta os efeitos conjunturais, seria também necessário repetir regularmente as pesquisas. Para analisar os efeitos da especialização do diploma e de sua origem em termos geográficos, é preciso dispor de pesquisas junto a uma vasta amostra de formandos. Para atender a essas exigências, foi criado, em 1975, o Observatoire National des Entrées dans la Vie Active (Affichard; Gensbittel, 1984). Dirigido pelo Céreq, o Observatoire pretendia, inicialmente, sondar toda uma geração de egressos do sistema educativo francês de um mesmo ano, nove meses após terem se formado (pesquisas de inserção) e quatro anos mais tarde (estudos de acompanhamento). Um primeiro ciclo de pesquisas de inserção ocorreu de 1976 a 1979, seguido do segundo ciclo, de 1980 a 1983, ao mesmo tempo em que se realizavam os primeiros inquéritos de acompanhamento (Flavigny; Grelet, 2012). Todas essas pesquisas foram feitas por via postal.
Com o dispositivo Génération 92, que inquiriu, em 1997, uma amostra de 27 mil jovens egressos em 1992 do sistema educativo, o Céreq operou a uma mudança de metodologia: uma amostra de jovens egressos no mesmo ano da formação inicial passou a ser entrevistada por telefone apenas três anos após a inserção deles no mercado de trabalho. Uma subamostra foi também entrevistada cinco, sete e dez anos após a formatura. Até o momento, seis pesquisas "Génération" já foram realizadas.

\section{ALGUMAS EXPERIÊNCIAS ATUAIS DE PESQUISAS FEITAS COM GRA- DUADOS DO ENSINO SUPERIOR}

\section{França}

As pesquisas realizadas pelo Céreq, por mais interessantes que possam ser no âmbito nacional, não permitem estudar detalhadamente o futuro dos formandos das distintas universidades. O Céreq, apoiado por sua rede de centros de pesquisas associados, bem que buscou, por intermédio de um Grupo de Trabalho formado em 1993, desenvolver um mecanismo que lhe permitisse sistematizar os estudos realizados pelas universidades. As primeiras observações do Centro resultaram em um documento que é, ao mesmo tempo, um guia metodológico e uma reflexão sobre a exploração e análise dos resultados - Parcours de formation et insertion professionnelle des étudiants, sources et méthodes, coordenado por Françoise Stoeffler-Kern e Daniel Martinelli. Esse grupo, filiado ao Céreq e a seus centros associados, não considerou uma evolução importante, que foi a iniciativa de as universidades, nos anos 1990, criarem seus próprios observatórios universitários, encarregados de acompanhar a trajetória de seus estudantes como, posteriormente, do desempenho deles na vida profissional.

Atualmente, cada uma das 75 universidades possui um observatório desse tipo e se 
reúnem numa associação - Observatoires de la Vie Etudiante. Uma primeira reunião desse grupo foi organizada em 1997, por iniciativa da Universidade da Borgonha, mas os estatutos da associação foram estabelecidos oficialmente apenas em dezembro de 2006. A associação possibilita o debate sobre as metodologias utilizadas e a conduta de trabalhos comparativos, os quais não são sempre fáceis, uma vez que os questionários são, em geral, específicos a cada estabelecimento. Esses problemas são idênticos àqueles já apontados em 1981 por Jean-Claude Eicher em relação às pesquisas-piloto realizadas nas Universidades de Nice, Lille e Toulouse, no início dos anos 1970 (Eicher; Paul, 1981).

Com o intuito de facilitar as comparações dos resultados, o Ministério do Ensino Superior da França tomou a iniciativa de entrevistar titulares de Masters (pela primeira vez em 2009 com os formandos de 2007). Esses estudos são dirigidos pelos observatórios das universidades. Os resultados da primeira pesquisa provocaram uma grande polêmica, em que o Ministério foi acusado de fazer comunicação política e de transformar os resultados em uma hit-parade das universidades, tendo como único indicador a taxa de desemprego. O corolário disso foi a rejeição do projeto da segunda pesquisa pelo Conselho Nacional de Informação $\stackrel{2}{5}$ Estatística, que apontou grandes riscos de desvio dos resultados, principalmente em relação as classificações. A comissão advertiu ainda sobre a ambiguidade entre a estatística pública e a comunicação política. ${ }^{7}$ Os resultados da segunda pesquisa também serão utilizados para estabelecer um ranking, apesar da existência de ₹ dúvidas sobre a representatividade da amostra (que envolveu 38\% dos graduados e não considerou os que prosseguiram os estudos) e sobre a interpretação dos dados, uma vez que nem todos os mercados de trabalho regionais oferecem as mesmas oportunidades.

${ }^{7}$ Ver, a esse propósito, as crônicas de Pierre Dubois em http://blog.educpros.fr/pierredubois. Nesse blog, são apresentadas as análises sobre o sistema francês, bastante criticado na comparação com outros dispositivos europeus, particularmente o italiano, discutido mais à frente.

\section{Grã-Bretanha}

A The Higher Education Statistics Agency (HESA) é a agência oficial encarregada de coletar, analisar e divulgar as informações quantitativas referentes ao ensino superior na Grã-Bretanha. Embora, desde 1963, algumas universidades já empreendessem algumas pesquisas sobre o primeiro emprego dos graduados, elas não revelaram uma visão clara e exaustiva das condições de acesso ao emprego (Clark, 1973).

Em 1993, um acordo entre os ministérios envolvidos, os conselhos encarregados do financiamento do ensino superior e as instituições de ensino superior deu origem à HESA, com o objetivo de coletar, analisar e divulgar as informações quantitativas referentes ao ensino superior. A HESA também surgiu em consequência de um "Livro Branco" que cobrava mais coerência nas estatísticas educacionais. Tratase de uma associação sem fins lucrativos, financiada pelas assinaturas de todas as Instituições de Ensino Superior (IES) do Reino Unido.

A HESA encarrega-se de dois tipos de estudos: uma pesquisa de inserção dos graduados seis meses após a formatura (The Destinations of Leavers from Higher Education, DLHE) e um estudo longitudinal realizado três anos e meio depois de formados. As pesquisas de inserção são feitas pelas IES, e os dados são enviados à HESA. Os estudos longitudinais, ao contrário das pesquisas de inserção, não são recenseamentos, mas são baseados numa amostra dos estudantes inquiridos na pesquisa de inserção. O quarto estudo longitudinal foi realizado em 2012-2013, com os formandos de 2008-2009. Os dados são coletados pelo IFF Research (instituto britânico privado de pesquisas).

No que diz respeito à coleta dos dados das pesquisas de inserção, as IES, independentemente de seu tamanho ou estatuto, seguem o procedimento estabelecido pela HESA. As informações recolhidas no momento dos levantamentos são acopladas ao registro acadêmico existente nas IES, em que se mencionam o diploma, a especialização e o modo de ensino dos estudantes. 
Em 2011-2012, a taxa de respostas dos 411.000 formandos foi estimada em $77 \%$. As modalidades dos levantamentos combinam questionários on line com entrevistas realizadas por telefone e pelo correio.

\section{Alemanha}

A Alemanha apresenta a situação paradoxal de um país de onde provêm importantes pesquisadores em matéria de estudos sobre os egressos do ensino superior e, ao mesmo tempo, contando com instituições que ficaram muito tempo fora do sistema unificado de pesquisas. Sem dúvida, trata-se de uma consequência do próprio sistema político federal que confere uma ampla autonomia aos Estados na organização de seus respectivos sistemas de ensino superior.

Teichler (1979) mostrou que, na Alemanha, nos fins dos anos 1970, não se dispunha de qualquer informação sistemática sobre o nível de formação da mão de obra, como também era desconhecido o número de egressos do ensino superior. Depois disso, inúmeras IES tomaram a iniciativa de entrar em contato com seus egressos (150 pesquisas foram realizadas nos anos 1990), mas demorou o surgimento de um sistema coordenado. Somente no final dos anos 1990, foram recompensados os esforços de Harald Schomburg (pesquisador de INCHER-Kassel), com a criação de um sistema parcialmente integrado de pesquisas sobre os egressos: o projeto Kooperationsprojekt Absolventenstudien $(K A O B)$. Nesse projeto, cada uma das universidades afiliadas à rede elabora um questionário a partir de um modelo comum estabelecido pelo INCHER-Kassel, responsável por compilar os resultados e realizar uma síntese geral. Algumas regiões, no entanto, não se associaram à rede e pouco mais de $50 \%$ de todos os graduados da Alemanha acabam participando do projeto.

A cooperação entre as IES e uma equipe de pesquisa tem dois objetivos principais: a profissionalização dos levantamentos junto aos egressos e a promoção da pesquisa sobre o ensino superior, por intermédio da disponibilização de uma base de dados anônimos provenientes de diferentes instituições.

Em 2012-2013, foram entrevistados os egressos de 2011. Esses graduados deverão ser novamente entrevistados em 2015-2016. De acordo com os autores desse dispositivo, essa segunda fase é necessária por quatro grandes razões. Primeiramente, porque os graduados alemães começam a trabalhar em um emprego que corresponde à sua formação somente de três a cinco anos depois de formados. Em segundo lugar, em alguns setores, é exigido um estágio de um ou dois anos antes de ingressar na profissão escolhida (em direito, por exemplo). Somente essa fase pode informar sobre as formações seguidas após a obtenção do diploma e sobre as etapas iniciais da carreira, o que possibilita também que se estabeleçam relações entre as condições iniciais de inserção e a continuação da carreira profissional.

As instituições solicitam a seus formandos que respondam às entrevistas por via postal ou eletrônica. Elas são responsáveis pela atualização das pastas de endereços. Os egressos podem responder ao questionário elaborado por INCHER-Kassel em linha ou por escrito. São enviados três lembretes, e as taxas de respostas das primeiras levas de questionários (cerca de 50\%) deixam os autores do projeto bastante otimistas.

Mesmo se o Ministério Federal de Educação e de Pesquisa da Alemanha não apareça em primeira linha nesses trabalhos, foi esse órgão que financiou o INCHER-Kassel para que as pesquisas fossem realizadas com egressos do ensino superior quatro a cinco anos após a formatura.

\section{Itália}

O exemplo italiano é particularmente interessante. A Itália se manteve, por muito tempo, afastada das pesquisas de egressos e 
apresenta hoje um sistema que é considerado por muitos, sobretudo por agências e pesquisadores internacionais, o melhor que existe atualmente.

Criado em 1994 por iniciativa do $O b$ servatorio Statistico dell'Università di Bologna (Observatório Estatístico da Universidade de Bolonha), AlmaLaurea experimentou um crescimento exponencial e reúne, atualmente, 78\% dos graduados universitários italianos. É administrado por um Consórcio das Universidades Italianas, com o apoio do Ministério da Educação, da Universidade e da Pesquisa. Os fundadores de AlmaLaurea souberam identificar as necessidades dos diferentes atores, de modo a estabelecer as incitações adequadas para cada um deles.

A ideia fundamental é criar uma base de dados confiável e atualizada de curricula vitae (CVs) dos egressos que seja acessível às empresas. Os estudantes, da sua parte, têm todo o interesse em ter os seus CVs nesse arquivo e, portanto, respondem aos questionários que os alimentam; as universidades, por sua vez, têm interesse em dispor de informações sobre o futuro dos seus alunos e em contar com dados confiáveis; por fim, as empresas têm interesse em utilizar os CVs dos egressos no intuito de ganhar tempo nos procedimentos de contratação. Em junho de 2013, a base de dados de AlmaLaurea dispunha de quase $1.800 .000 \mathrm{CVs}$ de egressos de 64 universidades italianas. Em termos práticos, os estudantes do último ano das universidades pertencentes ao consórcio são convidados a se conectarem ao portal de AlmaLaurea para obter sua identificação e senha. Nesse momento, eles fornecem uma primeira série de informações. Após a obtenção do diploma, suas universidades enviam os dados de seus registros acadêmicos, o que permite também controlar os dados fornecidos pelos estudantes. Essas informações compõem I a primeira parte dos CVs (dados pessoais e acadêmicos) e constituem a base do relatório elaborado anualmente, desde 1999, intitulado Profilo dei Laureati. Nele, são analisados dez conjuntos de informações, obtidas a partir dos registros acadêmicos (estudos realizados, dados demográficos e aprovação na universidade), ou então a partir dos questionários preenchidos pelos estudantes (origem social, condições de estudo, trabalho durante os estudos, avaliação da experiência universitária, competências linguísticas e informáticas, estudos em vista, projeto profissional). O relatório de 2013 ( $15^{\circ}$ da série) engloba 227.000 estudantes que terminaram seus estudos em 2012 em uma das 63 universidades do consórcio $(80 \%$ do total dos graduados italianos). A taxa de respostas aos questionários chega a 90\%. Todas as informações são acessíveis em linha, por universidade, por faculdade e por diploma. ${ }^{8}$

Um segundo relatório, Condizione oсcupazionale dei laureati, apresenta a situação dos egressos no mercado de trabalho, um ano, três anos e cinco anos depois da formatura. O relatório de $2013\left(15^{\circ}\right)$ abrange 400.000 graduados. As taxas de respostas são excelentes: $86 \%$ para a pesquisa de um ano, $80 \%$ para a de 3 anos e $77 \%$ para a de 5 anos após o diploma. Os dados englobam as informações da base dos CVs e as coletadas no momento da pesquisa: elas relatam a situação profissional atual, revelando se o egresso encontra-se desempregado ou não, o tipo de contrato, o salário, a profissão, as características da empresa, sua apreciação sobre a eficácia do seu diploma, a intensidade da utilização das competências adquiridas na universidade, dentre outras. As informações também são acessíveis em linha, segundo o ano de obtenção do diploma, por universidade, por faculdade e por tipo de diploma.

O AlmaLaurea é acolhido positivamente por inúmeros atores. Para Elizabeth King, diretora do setor de educação do Banco Mundial, o dispositivo permite a redução das dissonâncias de informações: dos empregadores que não conhecem as qualificações dos egressos, dos estudantes que não conhecem os resulta-

8 As referidas informações podem ser encontradas em <http://www.unibo.it/it/servizi-e-opportunita/servizi-online/ guida-servizi-online-studenti/almalaurea-questionario $>$. 
dos das universidades, dos egressos que não conhecem os empregos aos quais podem postular. Para Francisco Marmolejo, coordenador do ensino superior no Banco Mundial, e que diz já ter visto inúmeros dispositivos e metodologias pelo mundo afora, "nenhum apresenta o tipo de abordagem de AlmaLaurea", que resulta em tão ampla participação dos graduados nas pesquisas, em um forte compromisso da parte das IES, no interesse das empresas e da comunidade científica.

O sociólogo francês Pierre Dubois, criador de um dos primeiros observatórios universitários dos estudantes, critica fortemente o dispositivo francês de pesquisas de egressos em seu blog e não poupa elogios ao dispositivo italiano. Ele destaca, sobretudo, a alta taxa de respostas, a rapidez na divulgação dos resultados e a independência da organização com relação às autoridades políticas. Essa independência permite que se exponham claramente os problemas crescentes de inserção com os quais os egressos se confrontam.

Pelo lado contrário, Dubois considera que o sistema francês é muito lento na produção de resultados e, às vezes, sensível às pressões do poder político.

\section{OS PROJETOS INTERNACIONAIS}

\section{Columbus}

Columbus, uma associação fundada em 1987 pela Associação Europeia das Universidades e pela Associação das Universidades Latino-americanas a fim de promover a cooperação entre as universidades dos dois continentes, tomou a iniciativa de um projeto que visa ao desenvolvimento das pesquisas de egressos. Desse projeto, do qual participaram universidades e instituições das duas regiões (10 da América Latina e 11 da Europa), resultou um manual que apresenta as bases dos inquéritos de acompanhamento, os diferentes tipos de pesquisas, os principais elementos dos questionários de acompanhamento, e, para os empregadores, os elementos-chave para a realização das pesquisas junto aos egressos.

Dentre as instituições europeias que participaram do projeto, destacamos o Céreq, a Universidade de Ciências Sociais de Toulouse e a Universidade de Nice (pioneiras nas pesquisas de egressos), na França, a Universidade de Kassel, na Alemanha, e o consórcio AlmaLaurea, na Itália.

\section{DOIS PROJETOS DE PESQUISAS INTERNACIONAIS: CHEERS E RE- FLEX}

\section{CHEERS}

O objetivo do projeto de pesquisa Carrer after Higher Education: a European Research Study (CHEERS) era o de analisar a situação profissional dos egressos das IES em nove países europeus durante os cinco anos após a obtenção do diploma. A coordenação foi assumida por Ulrich Teichler e Harald Schomburg, ambos da Universidade de Kassel. Do final de 1998 a meados de 2000, cerca de 3.000 graduados de nove países da União Europeia, de um país da Associação Européia de Livre Comércio (Noruega) e de um país economicamente avançado fora da Europa (Japão) responderam a um questionário postal sobre as relações entre o ensino superior e o emprego. As respostas referiam-se à dimensão sociodemográfica, aos estudos concluídos, à transição dos estudos ao emprego, à primeira fase da carreira, aos vínculos entre a formação acadêmica e o emprego ocupado, à satisfação no emprego e também à visão retrospectiva sobre o ensino superior.

Tal pesquisa, dirigida a partir de um questionário único para todos os países (levando-se obviamente em conta as particularidades nacionais), permitia, pela primeira vez, examinar em que medida as relações entre a formação e o emprego eram semelhantes ou distintas em países desenvolvidos com as mesmas características. 


\section{REFLEX}

Research into Employment and professional Flexibility (REFLEX) é um projeto internacional de grande escala que cobriu dezesseis países. Preocupa-se com as demandas que a sociedade do conhecimento exerce sobre os egressos do ensino superior, e em saber em que medida o ensino superior transmite aos graduados as competências necessárias para satisfazer a essas demandas.

A pesquisa baseou-se em uma amostra representativa de 30.000 graduados, que foram entrevistados em 2005, cinco anos depois da formatura. Foi coordenada por Rolf van der Velden, da Universidade de Maastricht, Holanda, e participaram desse estudo pesquisadores de onze países: Alemanha, Áustria, Espanha, Finlândia, França, Itália, Japão, Noruega, Holanda, Reino Unido e Suíça. Essa vasta pesquisa articulou-se em torno de quatro interrogações: Que competências os estudantes do ensino superior buscam para integrar o mercado de trabalho? Quais são as que foram adquiridas e as que são exigidas pelos empregadores? Como as instituições de ensino superior os ajudam a desenvolvê-las? E, por conseguinte, quais são as tensões em jogo entre os estudantes, as instituições e os empregadores? (Allen; Van der Velden, 2011).

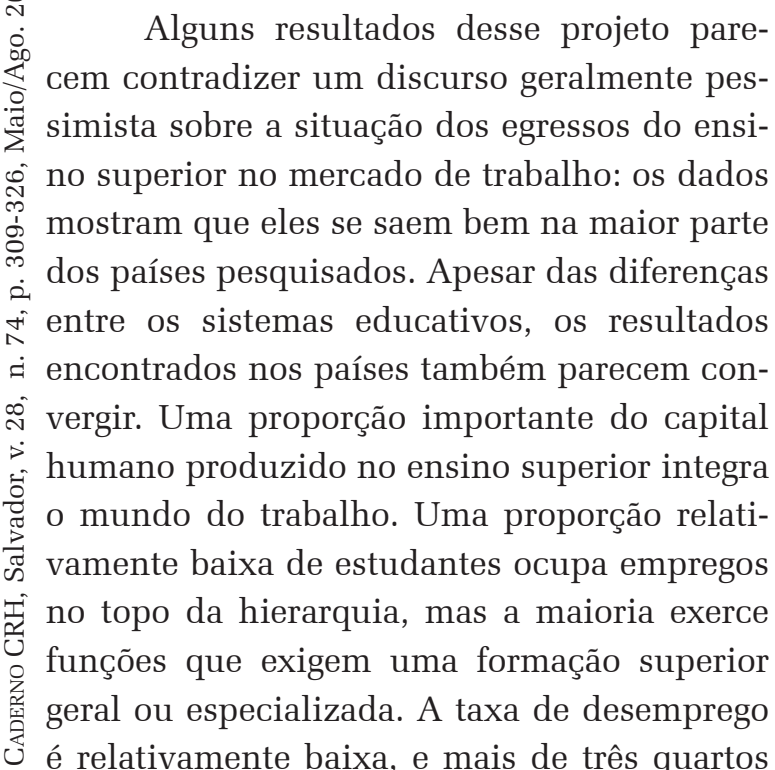

dos egressos alegam que seus conhecimentos e suas qualificações são suficientemente utilizados. Excetuando-se os "suspeitos habituais" (ciências humanas e sociais, e países do sul da Europa), a Grã-Bretanha apresenta-se como um país onde os egressos, mesmo cinco anos após o diploma, têm dificuldades em encontrar um emprego no qual suas competências sejam plenamente utilizadas. Isso pode ser explicado pelo fato de que o sistema de ensino superior britânico é bem menos ligado ao mundo do trabalho do que muitos dos sistemas de ensino superior do continente europeu (Allen; Van der Velden, 2011).

Os autores tiraram algumas recomendações sintéticas da pesquisa segundo os diferentes atores interessados. Dessa maneira, para a Comissão Européia, a principal mensagem é o interesse do dispositivo para se conhecer melhor os sistemas europeus de ensino superior, seus pontos comuns e suas fraquezas. Recomendam, ainda, a replicação do instrumento a cada cinco anos, em razão da necessidade de se acompanhar a expansão da globalização.

Aos governos nacionais os autores recomendam a necessidade de se reforçarem as orientações essenciais do ensino superior e de se incentivarem, durante os estudos, as experiências profissionais, desde que ligadas a eles. Quanto aos empregadores, a recomendação é a de que tomam mais consciência das reservas de capital humano à disposição, às vezes não utilizadas, bem como desenvolvam políticas que considerem a feminização do mercado de trabalho.

Quanto às IES, considerando o êxito dos egressos no mercado de trabalho, os autores as convidam para desenvolver programas de estudos mais exigentes. Os egressos tiram mais proveito de programas que insistem na especialização profissional. As avaliações continuadas parecem ser benéficas ao êxito profissional. Finalmente, as IES deveriam procurar dar sistematicamente créditos para as experiências profissionais relacionadas com os estudos.

Quanto aos estudantes, os autores os 
instigam a buscar as experiências de trabalho durante os estudos, pois elas se revelam benéficas no início da carreira. Destacam, ainda, a importância de se manterem numa boa rede de relacionamentos.

\section{O CASO BRASILEIRO}

\section{As primeiras iniciativas}

Uma das primeiras pesquisas de egressos foi a realizada junto aos graduados de direito da Faculdade de Direito do Vale do Paraíba, no Estado de São Paulo, a qual estudou a situação profissional de 122 graduados no período 1958-1976 (Paul, 1989).

Em 1982, a Coordenaçao de Aperfeiçoamento de Pessoal de Nível Superior (CAPES) desenvolveu uma pesquisa com graduados de 5 cursos (administração, biologia, educação, medicina e química) de 48 IES para os anos 1972, 1975, 1978 e 1980. Infelizmente, é difícil achar análises no Brasil que utilizaram os resultados dessa pesquisa. Uma exceção é a a dissertação de mestrado de Simões (1985).

Em 1986, a Universidade Federal do Ceará (UFC) promoveu uma pesquisa de egressos com os graduados de 17 cursos nos anos de 1978, 1980 e 1983. Provavelmente outras experiências foram desenvolvidas no país, lideradas por outras universidades, mas não foram divulgadas. Geraldo Ribas Machado, por exemplo, evoca, em sua tese de doutoramento (2010), quatro pesquisas dirigidas pela UFRGS junto aos graduados nos períodos 1970-72, 1973-75, 1976-78 e 1979-81.

Desse conjunto de trabalhos pioneiros, distinguem-se duas pesquisas: uma primeira dirigida em 1989-1990, na UFC, e a outra em 1991-1992, na Universidade de São Paulo. A primeira faz parte de um amplo projeto de pesquisa idealizado pela Coordenadoria de Análise Institucional e Avaliação da Pró-Reitoria de Planejamento da Universidade Federal do Ceará. Na busca da racionalidade do ensino superior brasileiro a partir do sistema cearense, o projeto envolvia as universidades existentes em Fortaleza e propunha-se a conhecer a realidade desse sistema a partir de três perspectivas importantes: a dos vestibulandos, a dos matriculados e a dos graduados.

O principal resultado da pesquisa mostra que, tanto do ponto de vista da procura dos cursos no momento do vestibular quanto da origem social dos alunos e do desempenho dos egressos no mercado de trabalho, não existe uma polarização "universidade pública" versus "universidade privada". Ficou clara a irrelevância de se compararem as universidades globalmente, sem levar em conta as dimensões "curso" e "turno", principais responsáveis pelas diferenças observadas. Existe, isso sim, uma continuidade entre os cursos e, no interior deles, entre as turmas (cursos diurnos e noturnos, cursos prestigiados ou menos prestigiados, de elite ou de classe pobre, de bom desempenho e de fraco desempenho no mercado de trabalho) (Paul e Ribeiro, 1997).

No que diz respeito à pesquisa com os egressos, foram entrevistados, em 1989, por via postal, os graduados de 1984 a 1986, concluintes dos 74 cursos superiores de Fortaleza naquele época, e foi analisada uma amostra representativa de 2.000 egressos. Também foi selecionada uma amostra de não-respondentes que foram posteriormente entrevistados por telefone a fim de garantir a confiabilidade das inferências e generalizações.

O projeto "A trajetória acadêmica e profissional dos alunos da USP" é um do conjunto de três pesquisas paralelas, desenvolvidas pelo Núcleo de Pesquisas sobre Ensino Superior da Universidade de São Paulo (NUPES/USP): a. início de um estudo longitudinal sobre a trajetória profissional dos alunos, pela aplicação de questionários ao universo de alunos que ingressaram na USP em 1991, nos cursos de graduação, em quatro áreas de formação selecionadas (cerca de mil entrevistas); b. estudo sobre a vida profissional dos estudantes de graduação formados pela USP nos últimos 
dez anos, com uma amostra de mil entrevistados, de quatro áreas de formação selecionadas; c. estudo sobre alunos e ex-alunos de pós-graduação da USP que iniciaram seus cursos nos últimos dez anos, em quatro áreas selecionadas (cerca de mil entrevistas).

O objetivo imediato desses estudos era desenvolver indicadores e permitir análises sobre a funcionalidade, o desempenho e a rentabilidade social e econômica dos cursos de graduação e pós-graduação da Universidade de São Paulo. Várias análises foram extraídas dessas pesquisas ${ }^{9}$ (Schwartzman; Castro, 1991; Schwartzman, 1992; Schwartzman et al., 1992; Castro; Paul, 1992)

Quanto às iniciativas institucionais, Geraldo Ribas Machado (2010) destaca "Um dos levantamentos pioneiros sobre egressos", estudo realizado pela Universidade de Brasília em 2006, junto a 614 formandos de 1994 a 2002. Ainda de acordo com Machado (2010), a UFRGS implantou, em novembro de 2003, um sistema de acompanhamento dos ex-alunos; também a Universidade Estadual de Londrina (UEL, 2006) inaugurou o seu portal do egresso para os 12.000 estudantes que se formaram entre 1998 e 2003; desse montante, 2.253 se registraram, disponibilizando dados pessoais, acadêmicos e profissionais.

Panorama das experiências em andamento

A observação das experiências em andamento evidencia a multiplicação dos "portais

${ }^{9}$ Geraldo Ribas Machado (2010) menciona inúmeros tra-

balhos ocasionais sobre egressos. Um deles é o de Mon-

teiro (1988), que entrevistou 640 egressos do curso de ad-

- ministração da UPE nos anos 1980; outro é o de Duarte

et al. (1999), em que os autores contataram, por telefone,

891 graduados de 1997-2001 da Universidade de Pelotas;

Gambardella et al. (2000), que entrevistaram 217 do cur-

so de nutrição da USP; Callegari (2001) com 110 egressos

em 1998 e 1999 de uma universidade particular do Rio

Grande do Sul. Machado também remete à tese de Teixeira

(2002), com 26 entrevistas com 252 graduados em 2000-

01 (de 24 cursos), o trabalho de Saurin (2006), junto a 52

egressos do curso de Administração da Universidade do

Oeste do Paraná em 1997 e 2004, como também o de An-

driola (2006), com 101 formandos dos cursos de graduação

de 2003 e 2004, ou ainda o trabalho de Pires (2008), junto

a 87 egressos da UNEB de 1987 a 2007. do egresso" em inúmeras IES. Examinando-se os sites acessíveis na internet, chega-se a identificar 32 instituições de ensino superior que possuem seu "Portal do egresso". São quatro universidades federais, três universidades estaduais, uma universidade municipal, dois institutos federais, onze universidades particulares e doze faculdades privadas. Essas iniciativas representam, sem dúvida, como é bem ilustrado no portal da Universidade Estadual de Londrina, uma "aproximação com os ex-alunos, intenção que foi reforçada pelas exigências do programa de autoavaliação institucional determinado pelo Sistema Nacional de Avaliação do Ensino Superior". Pode-se dizer, portanto, que essas iniciativas procuram responder a uma demanda explícita ou implícita das autoridades encarregadas das avaliações e das acreditações das IES. O Portal de Egressos do Instituto Federal de Educação, Ciência e Tecnologia do Rio Grande do Norte também expressa esse ponto de vista: "A Pesquisa de Acompanhamento de Egressos (PAE) é considerada pelo Ministério da Educação (MEC) como de fundamental importância para o desenvolvimento das políticas de educação e evolução das Instituições de Ensino no país".

Trata-se, portanto, mais de um procedimento administrativo do que de uma tomada de consciência generalizada sobre a importante contribuição das informações prestadas pelos egressos para a estratégia de formação das IES. Certas instituições até mesmo utilizam o portal para fazer propaganda dos cursos de pós-graduação ou de extensão universitária junto aos ex-alunos, propondo-lhes reduções.

Assim, a maioria dos portais não oferece aos ex-alunos mais do que um simples cadastramento. Alguns deles apresentam depoimentos de ex-alunos ou conselhos para quando se candidatarem a um emprego. Somente um portal disponibiliza uma análise dos dados recolhidos (Universidade Gama Filho, RJ), mas, ainda assim, os indicadores são bastante toscos. O êxito no mercado de trabalho só é ilustrado através de um gráfico, onde se dis- 
tinguem "ocupados”, “desempregados”, “aposentados" e "outros" segundo o curso seguido pelo egresso.

Alguns portais apresentam um questionário em linha, sugerindo que as informações recolhidas visam mais a obter opiniões sobre os cursos seguidos do que a conhecer a situação profissional dos egressos. Nota-se um interesse restrito das instituições em saber se os seus graduados atuam profissionalmente na área do curso em que se formaram: esse interesse limita-se à formulação de uma questão à qual os egressos devem responder "sim" ou "não" . Voltaremos a tratar mais adiante sobre os limites dessa avaliação.

\section{CONSIDERAÇÕES METODOLÓGICAS}

\section{O sistema}

As pesquisas não podem ser consideradas apenas como um dispositivo para satisfazer as autoridades responsáveis ou responder a um efeito de moda. As instituições devem convencer-se de que as pesquisas são ferramentas essenciais para melhorar o funcionamento do ensino superior e que proporcionam importantes informações aos estudantes e a suas famílias. Elas devem estar atentas à qualidade do questionário e das respostas, como também à qualidade do tratamento das informações solicitadas.

Duas armadilhas devem ser evitadas: a) as iniciativas individuais de IES que lançam estudos a partir de seu próprio questionário, impedindo qualquer possibilidade de comparação dos resultados, e b) um sistema centralizado em que as IES não se sentem participantes. Nesse caso, as taxas de respostas correm o risco de ser mais baixas, e as IES não se apropriarão dos resultados para uso interno.

Nesse contexto, a experiência de AlmaLaurea aparece como um modelo capaz de envolver todos os atores (IES, estudantes, empresas, Ministério do Ensino Superior) e alcançar uma elevada taxa de respostas aos questioná- rios, informações confiáveis e de qualidade, e um melhor funcionamento do mercado de trabalho, aproximando oferta e demanda de trabalho. A vantagem do sistema de AlmaLaurea está em utilizar os dados dos registros acadêmicos e, dessa forma, conseguir reduzir o tamanho do questionário e garantir a qualidade das informações sobre os diplomas obtidos.

Uma condição essencial ao funcionamento do sistema é a atualização constante dos endereços, sendo que, hoje em dia, o endereço eletrônico do egresso tornou-se o mais importante. Mas o conhecimento de um número de telefone também pode ajudar no contato com os egressos para verificação ou aprofundamento de certas informações.

O recurso a um questionário on line permite que se disponha de um sistema pouco oneroso (as IES brasileiras parecem tê-lo entendido muito bem): sem inquéritos impressos, sem custo por via postal, sem custo de chamadas telefônicas, sem custo de tratamento dos dados. Mas é necessário incentivar os egressos a se conectarem regularmente. Também, nesse ponto, o sistema de AlmaLaurea, que disponibiliza os CVs em linha, parece oferecer uma incitação eficaz. Os pedidos para se conectarem e atualizarem as informações podem ser feitos por mensagens eletrônicas, tweeter, ou pelas redes sociais, que são cada vez mais utilizadas pelas associações de ex-alunos.

Para que as IES se apropriem das informações, elas devem dispor, em seus estabelecimentos, de pessoal capacitado para analisá -las e repassá-las aos alunos e professores que não são necessariamente familiarizados com essas áreas. No que diz respeito aos estudantes, é preciso que trabalhem com os serviços de orientação mais adequados para ajudar na escolha da carreira (mesmo se for necessário distanciar-se um pouco para levar em conta as possíveis mudanças no mercado de trabalho). Quanto aos docentes, é desejável que os dados recolhidos alimentem as reflexões sobre as formações a serem desenvolvidas, transformadas ou até mesmo encerradas, o mesmo ocorrendo 
em relação aos instrumentos pedagógicos a serem implementados.

Outro ponto importante refere-se à periodicidade das pesquisas. As informações só podem ser significativas se restituídas em uma comparação intertemporal dos resultados, de modo a salientar as evoluções.

A questão da periodicidade das pesquisas e das análises continua aberta. Um dispositivo permanente, em que os egressos atualizam constantemente o seu currículo, reduz ou até pode eliminar a questão da frequência das pesquisas, uma vez que a informação é inserida de forma contínua. Mas a questão da periodicidade da análise continua sem resposta: quanto tempo após a graduação é conveniente esperar para analisar a situação?

Nota-se, aqui, muitas vezes, uma contradição entre dois tempos diferentes: a dos decididores políticos, que querem informações rápidas, e a dos pesquisadores que, levando em conta as dinâmicas internas do mercado de trabalho dos egressos, preferem esperar pelo menos três anos para avaliar a situação (conferir o dispositivo alemão). Um acordo pode ser encontrado na articulação de diferentes levas de pesquisas, como o dispositivo Génération do Céreq na França, ou as análises de AlmaLaurea na Itália, efetuadas um, três e cinco 을 anos depois da formatura).

Enfim, é importante que as informações coletadas sejam reunidas em bancos de dados acessíveis à comunidade científica. Os pesquisadores poderão tirar ensinamentos teóricos das informações coletadas, contribuir na identificação das tendências subjacentes e melho‡ rar os instrumentos de investigação.

\section{A população e o questionário}

A população a ser atingida pelos inquéritos junto aos egressos deve ser definida claramente a partir do tipo de diploma e da data de sua obtenção. O diploma garante certa homogeneidade, que dá sentido aos resultados (mesmo se o diploma de referência contituir somente um dos diplomas obtidos por certos egressos, que voltaram a estudar ou que foram reorientados, por exemplo). O estabelecimento de uma data comum de obtenção do diploma facilita a análise, oferecendo um mercado de trabalho com condições homogêneas no momento da formatura (mesmo se alguns egressos já trabalhavam quando da obtenção do diploma).

Existem, hoje, muitos exemplos de questionários corroborados por inúmeras pesquisas. Aconselhamos a leitura do guia metodológico elaborado por Harald Schomburg na Universidade de Kassel (2003), ou o manual preparado pelo projeto Columbus (Columbus, 2006). O tamanho do questionário dependerá dos objetivos do projeto e dos meios colocados à disposição.

Se quisermos exemplificar com o questionário utilizado nos projetos CHEERS, veremos que ele continha dez seções que abrangiam:

a. Os estudos concluídos antes daqueles relativos ao diploma de referência.

b. Os diferentes estudos universitários seguidos.

c. A procura de emprego e a lista sequencial das atividades profissionais.

d. As atividades e o emprego no momento da pesquisa.

e. As competências e sua utilização.

f. Relações entre o ensino superior e o emprego.

g. Expectativas em relação ao trabalho e a satisfação no emprego.

h. Formação ulterior.

i. Dados sociobiográficos.

j. Avaliação retrospectiva dos estudos realizados

Cada uma das seções pode ser mais ou menos detalhada, ou mesmo suprimida, dependendo das perspectivas da pesquisa. É verdade que, quanto mais longo for o questionário, mais difícil será atingir uma taxa de resposta elevada. Mas devemos mencionar que o questionário de AlmaLaurea, que obtém, conforme já vimos, as excelentes taxas de respos- 
ta, inclui cerca de 45 questões (algumas das quais com mais de 10 itens).

Convém lembrar também que é melhor deixar as perguntas mais fáceis de responder para o fim do questionário (por exemplo, dados sociobiográficos, avaliação retrospectiva dos estudos: "se tivesse que recomeçar, escolheria o mesmo diploma?”).

Tendo em vista alguns questionários reproduzidos nos portais das IES brasileiras, algumas observações podem ser feitas. Por um lado, é melhor combinar informações precisas (salário) com uma opinião: "Em que medida você está satisfeito com o seu emprego atual?" (nota de 1 para "muito insatisfeito" a cinco para "muito satisfeito"). Isso permite combinar a informação objetiva sobre a situação e o caráter subjetivo da sua percepção. Além disso, é preferível utilizar as escalas de Likert, que aperfeiçoam as respostas de escolha binária (sim, não). As questões do projeto CHEERS utilizaram as escalas de Lickert com 5 níveis, e o projeto REFLEX recorreu a uma escala de até sete posições para certos ítens.

Por fim, uma cilada a ser evitada e que está profundamente enraizada na mente dos diferentes atores (docentes, poderes públicos, famílias) é a do uso demasiadamente simplista da adequação entre a área do emprego e a da formação.

Já havíamos lembrado, neste artigo, os limites do conceito de desvio ocupacional (Paul, 1989), que supõem uma visão extremamente limitada das competências desenvolvidas através da educação e não leva em conta as dinâmicas internas do mercado de trabalho (principalmente com relação aos gostos do trabalhador, à estrutura das carreiras e ao nível de remuneração). Havíamos dado como exemplo o curso de administração, que apresentava, em uma dada pesquisa, a taxa de desvio ocupacional mais elevada e também os salários mais elevados.

Para ilustrar a complexidade do tema, apresentaremos a abordagem do projeto CHEERS que recorreu a cinco dimensões: a. Se você levar em consideração todas as tarefas do seu trabalho atual, em que medida você usa os conhecimentos e as competências adquiridas durante os seus estudos? (de 1 “não uso" a 5 "em grande escala”).

b. Como você caracteriza a relação entre a sua área de formação e a área de trabalho? (Minha área de formação era a única possível /a melhor opção; outras áreas também podiam preparar bem para esse domínio de trabalho; uma outra área teria sido mais útil; a área de formação não tem muita importância; os meus estudos superiores não estão em nada ligados à minha área profissional).

c. Se você considerar todas as dimensões do seu emprego (status, posição, salário, tarefas, etc.), em que medida o seu emprego e o seu trabalho estão apropriados ao seu nível de educação? (de 1 "nem um pouco apropriados" a 5 "totalmente apropriados”).

d. Qual é o nível de formação mais apropriado para o seu emprego em comparação ao nível do seu diploma do ano de referência da pesquisa? (um nível mais elevado do que o meu; o mesmo nível; um nível de ensino superior mais fraco; sem nenhum diploma universitário).

e. Se você considerar o seu emprego como pouco apropriado e sem ligação com o seu diploma, por que o escolheu (várias respostas possíveis)? (não pude encontrar um emprego mais apropriado; tenho melhores oportunidades de carreira ocupando este emprego; prefiro um emprego que não esteja intimamente relacionado com os meus estudos; fui promovido a uma posição menos ligada aos meus estudos do que a anterior; eu posso ter um salário mais alto no meu emprego atual; meu emprego atual oferece mais segurança; meu emprego atual é mais interessante; o meu emprego atual oferece possibilidades de trabalhar meio período; meu emprego atual permite que eu trabalhe em um lugar que eu prefiro; o meu emprego atual permite que leve em conta minhas obrigações familiares; no início da carreira que pretendo seguir, eu 
devo aceitar um emprego pouco relacionado com os meus estudos).

\section{CONCLUSÃO}

Esse panorama histórico e internacional de pesquisas realizadas junto aos egressos do ensino superior revela uma evolução efetiva nos métodos de investigação. Se o sistema italiano nos leva a refletir por oferecer taxas de respostas inigualáveis, além de rapidez e comparabilidade dos resultados, deve-se também avaliar sua utilização efetiva pelos diferentes atores e seu impacto sobre as decisões tomadas por uns e outros. É verdade que a Itália tem a vantagem de possuir um ensino superior de dimensão relativamente modesta, sobretudo se comparada à do Brasil.

No Brasil, podem ser encontradas situações bastante díspares, segundo as regiões e o status das universidades. As universidades do sul do país parecem ter sido mais propensas a desenvolver o "Portal do Egresso". O mesmo ocorreu em relação às universidades particulares. Um primeiro ponto de recomendação seria o de promover sistemas harmonizados de coleta e de tratamento das informações no âmbito dos Estados, o que também permitiria uma 농 maior homogeneidade dos mercados de tra․ balho. No que diz respeito ao segundo ponto, $\dot{\circ}$ as instituições privadas, mais sujeitas à concorrência, têm a tendência de se mostrar mais próximas de seus formandos e mais sensíveis às condições de inserção dos ex-alunos. No entanto, o aparente baixo nível de utilização das ז informações poderia sugerir uma abordagem $\therefore$ de tipo marketing. Por outro lado, as instituiจ ções federais parecem se mostrar bastante con$\vec{s}$ servadoras quanto a esse aspecto, pois raras são aquelas que oferecem tal portal.

De qualquer maneira, a aceitação do processo de coleta de informações de ex-alunos e a internalização de tais informações por parte das instituições, na sua abordagem estratégica, pressupõem uma tomada de consciên- cia de toda a comunidade acadêmica e uma formação adequada dos funcionários universitários. Parece que o desinteresse, ou até mesmo a desconfiança da comunidade acadêmica em relação a essa abordagem, pode ter sua origem na ideia, ainda presente em algumas pessoas, de que a universidade não deve se preocupar com a economia nem com as expectativas dos empregadores. No entanto, os ensinamentos de um projeto internacional, como o REFLEX, confirmam a utilidade, para os alunos, de que os empregadores potenciais sejam associados à formação, principalmente através de projetos e (ou) estágios. Além disso, os depoimentos colhidos junto aos empregadores fornecem elementos úteis e complementares às informações dadas pelos egressos.

Em um mercado de trabalho com exigências que evoluem constantemente, as IES devem repensar regularmente a sua oferta de formação e sua pedagogia. Se as pesquisas junto aos egressos não constituem a única fonte dessa reflexão, elas podem representar um elemento essencial para que ela ocorra. É por isso que um melhor conhecimento de seus processos e de suas contribuições pode vir a ser uma ajuda importante para melhorar o funcionamento das instituições.

Enviado para publicação em 09 de dezembro de 2014 Aceito em 18 de março de 2015

\section{REFERÊNCIAS}

AFFICHARD, J.; GENSBITTEL, M. H. Mesurer l'entrée des jeunes dans la vie active. Formation-Emploi, n. 8, p. 61-71, 1984

ALLEN, J.; VAN DER VELDEN, R. (Eds.) The flexible professional in the Knowledge Society: new challenges for higher education. Higher Education Dynamics, Dordrecht: Springer. n. 35, 2011.

ANDRIOLA, W.B. Avaliação diagnóstico de 2003 e 2004 dos cursos de graduação da UFC. Revista da Rede de Avaliação Institucional da Educação Superior. Campinas, 2006.

CALLEGARI, M.M. A inserção profissional de egressos universitários. Porto Alegre: PUCS-Faculdade de Psicologia (dissertação), 2001.

CAPELLE, O. Les stages effectués dans les universités en 2011-2012. Note d'information, Enseignement supérieur et Recherche, 14-02, abr, 2014. Disponível em: < http:// 
cache.media.enseignementsup-recherche.gouv.fr/ file/2014/74/3/NI_ESR_14_02_v3_317743.pdf >.

CLARK, C.R. A Study of graduate employment. British Journal of Educational Studies, v. 21, n. 2, jun., p. 156-171, 1973.

COLUMBUS. Graduate follow-up instruments and recommendations manual. GRADUA2 Network/ Columbus Association, ALFA, Europe Aid Co-Operation Office, 2006.

DUARTE, M.C. et al. Avaliação institucional: um processo em consolidacão na universidade católica de Pelotas. In: SILVA, I. B.; DALLA ROSA, S. C. (2003). Avaliação institucional integrada: os dez anos do PAIUNG. Ed. Ijui, p. 169-193, 1999.

DUBOIS, P. Crônicas. Disponível em: < http:/blog.educpro. fr/pierredubois $>$.

EICHER, J. C.; PAUL, J. J. Analyse et confrontation des résultats de quelques enquêtes longitudinales. In: L'insertion professionnelle des jeunes à la sortie des études postsecondaires. Dossier de l'Institut des Sciences du Travail, Université Catholique de Louvain, n. 2, p. 153191, 1981.

EPIPHANE, D.; JUGNOT, S. Harmoniser les mesures de l'insertion des diplômés du supérieur. Bref Céreq, n. 291, 2011.

FLAVIGNY, P.O.; GRELET, Y. Le Céreq, 40 ans d'enquêtes sur l'insertion des jeunes. In: Mobilités et changements de catégories: portées et limites des données longitudinales. Relief Céreq, n. 37, p. 29-38, 2012.

FRENCH, E.B.; COOK, R.F. The College Graduate: his early employment and job satisfaction. The College Placement Council, Research Information Center, 1969.

GAMBARDELLA, A.M.D. et al. Situação profissional dos egressos de um curso de nutrição. Revista de nutrição. Campinas, v. 13, n. 1, 2000.

MAGALHÃES CASTRO, M.H.; PAUL, J.J. As atividades profissionais do ex-alunos da USP. NUPES, Análises preliminares. 4/92, 1992.

MONTEIRO, A.L.R. Avaliação do curso de graduação em administração da FCAP por seus egressos. Recife: UPEFCAP, 1988

PARNES, H. L'enquête diachronique et ce qu'elle peut apporter à la planification de l'éducation. Comunicação apresentada no seminário do IIPE sobre L'enseignement supérieur et l'emploi, UNESCO, Paris, 1978.

PAUL, J. J. Algumas reflexões sobre as relações entre o ensino superior e o mercado de trabalho no Brasil. Documento de trabalho 8/89, NUPES, Universidade de São Paulo, 60p. 1989.

; DIAS RIBEIRO, Z. O Mercado de trabalho para os egressos do ensino superior de Fortaleza. Documento de trabalho 1/97, NUPES, Universidade de São Paulo, 60p. 1997.

PIRES, R.C.M. A formação inicial do professor pesquisador universitário no programa institucional de bolsas de iniciação científica PIBIC/CNPq e a prática profissional do seus egressos: um estudo de caso na Universidade do Estado da Bahia. Porto Alegre, Programa de graduação da Faculdade de educação da UFRGS, 2008.
RIBAS MACHADO, G. Perfil do egresso da Universidade Federal do Rio Grande do Sul. Porto Alegre, 2010.

ROSSI, R.J. et al. Methodology of the Project TALENT - 11 Year Follow-Up Study. American Institute For Research, Palo-Alto, California, 1976.

SANYAL, B. et al. Higher education and labour market in Zambia: expectations and performance. IIEP, Unesco, Paris, 1976.

; JOZEFOWICZ, A. Graduate employment and planning of higher education in Poland. IIEP, Unesco, Paris, 1978.

SAURIN, G. Educação superior e mercado de trabalho: um estudo dos egressos do curso de graduacão em administração da UNIOESTE de Cascavel-PR. UNIOESTE: Pós-graduação em Desenvolvimento regional e agronegócio.

SCHOMBURG, H.; TEICHLER, U. (Eds.) Higher education and graduate employment in Europe. Results from graduate surveys from twelve countries. Dordrecht, Springer, 2006.

; . (Eds.) Employability and mobility of bachelor graduates in Europe. Key Results of the Bologna Process. Sense Publishers, 2011.

SCHWARTZMAN, S.; MAGALHÃES CASTRO, M.H. de A trajetória acadêmica profissional dos alunos da USP. NUPES, Documento de Trabalho, n², 1991.

Os estudantes de ciências sociais. NUPES, Análises preliminares, 5/92, 1992.

et al. A construção das amostras. NUPES, Análises preliminares, 6/92, 1992.

SEWELL, William H.; HAUSER, Robert M. Education, occupation, and earnings. Achievement in the early career. Academic Press Inc, New York, New York., 1975. Disponível em http://eric.ed.gov/?id=ed116041

SIMOES, R.A. Ensino superior e mercado de trabalho (Dissertação, UFC, CAEN, Fortaleza, 1985.

STOEFFLER-KERN, F.; MARTINELLI, D. (Eds.) Parcours de formation et insertion professionnelle des étudiants, sources et méthodes. Document Céreq, n. 134, 1998.

TEICHLER, U. Higher education and labour market in the Federal Republic of Germany. Comunicaça apresentada no Seminário IIPE-IREDU sobre L'éducation, le travail et l'emploi. Dijon, dezembro, 1979.

Bologna - Motor or stumbling block for the mobility and employability of graduates? In: SCHOMBURG, Harald; TEICHLER, Ulrich (Eds.). Employability and mobility of bachelor graduates in Europe. Key Results of the Bologna Process. Sense Publishers, p. 3-41, 2011.

TEIXEIRA, M.A.P. A experiência de transição entre a universidade e o mercado de trabalho na adultez jovem. Porto Alegre: UFRGS, Pós-Graduação em Psicologia do desenvolvimento. (2002). 


\section{HIGHER EDUCATION GRADUATES MONITORING: Brazilian and international experiences}

\author{
Jean-Jacques Paul
}

This article provides an overview of the various experiences of monitoring of higher education graduates, highlighting the methodologies used in different countries or international projects. Monitoring devices are the result of government policies or autonomous institutions and are intended to give greater visibility to the higher education system increasingly complex. Providing essential data for the evaluation of the results of educational systems, monitoring systems achieved the best health indicators in the Italian case, AlmaLaurea. In Brazil there are disparate experiences, starting in the 1970s, through the studies at USP and UFC in the early 1990s to the current stage with the proliferation of graduates' portals. The methodological requirements of monitoring, as shown by experience: systematic and participatory nature, institutionally; regular intervals and continuous updating; use of information technologies for data collection; clear and appropriate definition of the target population according to the types of diplomas; production scales adequate for evaluation of occupational destinations and its relation to training; availability of databases for the academic community.

KEY WORDS: Higher education. Monitoring systems. evaluation. Graduates. Occupational destinations.

\section{SUIVI DES DIPLOMES DE L'ENSEIGNEMENT SUPERIEUR: expériences brésilienne et internationale}

Jean-Jacques Paul

Cet article donne un aperçu des diverses expériences de suivi des diplômés de l'enseignement supérieur, en soulignant les méthodologies utilisées dans différents pays où des projets internationaux. Les dispositifs d'enquête sont le résultat de politiques gouvernementales ou d' institutions autonomes et sont destinés à donner une plus grande visibilité à un système d'enseignement supérieur de plus en plus complexe. Fournissant des données essentielles pour l'évaluation des résultats des systèmes éducatifs, les dispositifs d'enquête ont obtenu les meilleurs indicateurs dans le cas italien, AlmaLaurea. Au Brésil, il ya des expériences disparates, qui ont commencé dans les années 1970, à travers des études à l'USP et l'UFC dans le début des années 1990 jusqu'au stade actuel de la prolifération des portails pour les diplômés. Les exigences méthodologiques de suivi selon les observations de l'expérience: caractère institutionnel, systématique et participatif; intervalles réguliers et mise à jour continue; utilisation des technologies de l'information pour la collecte de données; définition claire et appropriée de la population cible selon les types de diplômes; échelles adéquates pour l'évaluation des situations professionnelles et leurs liens avec la formation; disponibilité des bases de données pour la communauté universitaire.

MotS CLÉs: Enseignement supérieur. Systèmes de suivi. Évaluation. Diplômés. Destinations professionnelles.

Jean-Jacques Paul - Economista da educação. Professor e pesquisador do IREDU, da Universidade da Borgonha em Dijon (França). Desde setembro de 2012, ocupa o cargo de reitor-adjunto da Universidade Galatasaray, em Istambul. Anteriormente, ocupou funções idênticas na Universidade Real de Direito e de Ciências Econômicas de Phnom Penh (Camboja). Sua carreira de professor, de pesquisador e de consultoria levaram-no a dividir seu tempo, de 1978 a 2008, entre a Universidade da Borgonha e cerca de vinte outros países. É autor de oito livros, de uma centena de artigos e comunicações, e dirigiu vinte teses de doutoramento.

Ele foi principalmente vice-presidente da Universidade da Borgonha, decano da faculdade de economia e de administração desta universidade e diretor do Instituto de Pesquisas CNRS sobre a economia da educação (Irédu). No Brasil, dirigiu pesquisas sobre o ensino superior no âmbito da Universidade Federal do Ceará, do NUPES na Universidade de São Paulo, e em cooperação com a Universidade Federal do Rio de Janeiro. 